\title{
Platelet Volume Is Reduced In Metastasing Breast Cancer: Blood Profiles Reveal Significant Shifts
}

This article was published in the following Dove Press journal:

Cancer Management and Research

\author{
Ming-ming $\mathrm{Li}^{1}{ }^{1} *$ \\ Chen-xi Yue ${ }^{1, *}$ \\ Shuang Fu' \\ Xin Zhang' \\ Chang-Jiu Zhao ${ }^{2}$ \\ Rui-tao Wang $\left(\mathbb{D}^{\prime}\right.$ \\ 'Department of Internal Medicine, \\ Harbin Medical University Cancer \\ Hospital, Harbin Medical University, \\ Harbin, Heilongjiang I5008I, People's \\ Republic of China; ${ }^{2}$ Department of \\ Nuclear Medicine, The First Affiliated \\ Hospital of Harbin Medical University, \\ Harbin, Heilongjiang I5000I, People's \\ Republic of China
}

*These authors contributed equally to this work

\begin{abstract}
Background: Platelets play a crucial role in breast cancer $(\mathrm{BC})$ progression and metastases. Mean platelet volume (MPV) is an indicator of platelet activation. The aim of the present study was to assess whether there is a difference in MPV between patients with metastatic $\mathrm{BC}$ with liver metastases and those with $\mathrm{BC}$ without liver metastases.

Methods: Between January 2014 and December 2017, 211 metastatic BC patients with synchronous liver metastases and $215 \mathrm{BC}$ patients without metastases were retrospectively analyzed. Patients' clinicopathological characteristics data were collected.

Results: MPV levels were reduced in patients with liver metastases compared with those in patients without liver metastases. There were significant differences in MPV levels according to liver metastases status both in premenopausal and in postmenopausal non-TNBC or non-HER2+ patients. Moreover, in postmenopausal HER2+ or TNBC patients, MPV levels were lower in patients with liver metastases compared with those in patients without liver metastases. In the group with non-liver metastasis, platelet distribution width was significantly associated with tumor $\mathrm{N}$ stage. In addition, the prevalence of BC liver metastases decreased as MPV quartiles increased. After adjusting for other risk factors, the odds ratios for liver metastases according to MPV quartiles were $1.000,0.267$ (0.134-0.530), $0.072(0.034-0.152)$, and 0.137 (0.066-0.281), respectively.

Conclusion: MPV is reduced in BC patients with liver metastases compared with that in BC patients without metastases. Moreover, MPV is independently associated with the presence of liver metastases.
\end{abstract}

Keywords: breast cancer, liver metastases, mean platelet volume, patient stratification, blood profiling

\section{Introduction}

Breast cancer (BC) is the most frequently diagnosed cancer and is the leading cause of cancer-related deaths among women. ${ }^{1}$ Liver metastasis occurs in $15 \%$ of newly diagnosed $\mathrm{BC}$ patients and has a survival time of 4-8 months. ${ }^{2}$ Therefore, identification of biomarkers of $\mathrm{BC}$ with liver metastases is urgently needed.

Currently, there is a lack of reliable predictive and prognostic biomarkers that hamper effective implementation of individualised patient stratification essential for tailoring treatment decisions. ${ }^{3}$ Recent studies demonstrated that premenopausal women have lower survival rates and respond less to conventional chemotherapy compared to the majority of postmenopausal BC. Patient stratification approach utilising menopausal status will result in improved clinical utility of biomarker patterns. $^{4,5}$ In addition, liquid biopsies have encouraged researchers to develop noninvasive signatures that can be exploited as biomarkers for metastatic evaluation. ${ }^{6}$ 
There is plenty of evidence that demonstrated that platelet activation and platelet-cancer cell interaction are crucial for cancer metastases. Thrombocytosis correlates with a worse prognosis in many cancers, such as gastric, pancreatic, colorectal, ovarian, and endometrial cancer. ${ }^{7-11}$ A commonly used measurement of platelet size in clinical practice is mean platelet volume (MPV). MPV is an indicator of platelet activation. ${ }^{12}$ Alteration of MPV levels in breast, lung, gastric, colon, and ovarian cancer has been reported. ${ }^{13-16}$ However, its clinical implication in $\mathrm{BC}$ liver metastases has not been investigated.

The current study was to evaluate whether there is a difference in MPV between patients with metastatic BC with liver metastases and those with $\mathrm{BC}$ without liver metastases.

\section{Methods}

\section{Study Population}

211 BC patients with synchronous liver metastases and 215 BC patients without metastases at the Harbin Medical University Cancer Hospital between January 2014 and December 2017 were screened for enrolment in the present study by reviewing electronic charts. All BC patients received MRI scanning of head, CT lung screening, abdominal enhanced MRI, and ECT evaluation of skeletal metastases to rule out distant metastases. All BC patients without metastases undergone complete surgical resection. The diagnosis of $\mathrm{BC}$ was confirmed by histology. Synchronous liver metastases were defined as a time interval between the diagnosis of the primary $\mathrm{BC}$ and development of liver metastases within 6 months. None of the patients had received surgical treatment, radiotherapy or chemotherapy before enrolment. Patient demographics and clinicopathologic data were obtained from the databases in our hospital. The patients with hematological disorders and medical treatment with acetylic salicylic acid were excluded from our study.

The study protocol was approved by the Ethics Committee of the Institutional Ethics Review Board of Harbin Medical University Cancer Hospital (2018-x0352), and a signed informed consent was obtained from each patient. This study was conducted in accordance with the Declaration of Helsinki.

\section{Statistical Analysis}

The statistical tests were carried out using SPSS version 25.0 software (SPSS Inc., Chicago, IL, USA). Normally distributed continuous variables between two groups were compared with the independent $t$-test or Mann-Whitney's
U-test. Categorical variables were compared with the Chisquare test. All subjects were stratified into quartiles according to their MPV levels. The MPV quartiles were quartile $1(\mathrm{Q} 1)(\leq 7.7 \mathrm{fL})$, quartile $2(\mathrm{Q} 2)(7.8-8.4 \mathrm{fL})$, quartile $3(\mathrm{Q} 3)(8.5-9.3 \mathrm{fL})$, quartile $4(\mathrm{Q} 4)(\geq 9.4 \mathrm{fL})$. The odds ratios (ORs) and $95 \%$ confidence intervals (95\% CIs) for liver metastasis were calculated after adjusting for confounding variables across MPV quartiles using multivariate logistic regression analysis. $\mathrm{P}<0.05$ was considered to indicate a statistically significant difference.

\section{Results}

We enrolled $426 \mathrm{BC}$ patients in this retrospective study. The median age of patients was 52 years (range: $21-80$ years). The baseline clinicopathological characteristics of patients are listed in Table 1. The patients with liver metastases were older and had lower body mass index, haemoglobin, and MPV, and higher lactate dehydrogenase,

Table I Baseline Characteristics Of BC Patients

\begin{tabular}{|c|c|c|c|}
\hline Variables & $\begin{array}{l}\text { With Liver } \\
\text { Metastases }\end{array}$ & $\begin{array}{l}\text { Without Liver } \\
\text { Metastases }\end{array}$ & $\begin{array}{l}P \\
\text { value }\end{array}$ \\
\hline $\mathrm{N}$ & 211 & 215 & \\
\hline Age (years) & $52.9(8.8)$ & $50.4(9.8)$ & 0.006 \\
\hline BMI $\left(\mathrm{kg} / \mathrm{m}^{2}\right)$ & $23.4(3.4)$ & $24.2(3.0)$ & 0.007 \\
\hline \multicolumn{4}{|l|}{ Menopausal status } \\
\hline (Post, \%) & $138(65.4)$ & $134(62.3)$ & 0.234 \\
\hline FPG (mmol/L) & $5.20(4.90-5.83)$ & $5.20(4.90-5.60)$ & 0.205 \\
\hline Albumin $(g / L)$ & $44.0(5.3)$ & $45.0(5.3)$ & 0.063 \\
\hline Creatinine (umol/L) & $68.0(18.3)$ & $71.2(15.6)$ & 0.053 \\
\hline WBC $\left(\times 10^{9} / \mathrm{L}\right)$ & $6.2(2.1)$ & $6.1(1.8)$ & 0.423 \\
\hline Haemoglobin (g/dL) & $124.8(16.1)$ & $134.6(12.2)$ & $<0.001$ \\
\hline Platelet count $\left(\times 10^{9} / \mathrm{L}\right)$ & $239.7(81.2)$ & $235.5(51.8)$ & 0.524 \\
\hline MPV (fL) & $8.2(1.4)$ & $9.1(1.2)$ & $<0.001$ \\
\hline PDW (\%) & $16.9(1.5)$ & $16.8(1.0)$ & 0.137 \\
\hline Lactate & 200.0 & 153.0 & $<0.001$ \\
\hline dehydrogenase (U/L) & $(157.2-286.0)$ & $(138.0-172.0)$ & \\
\hline CEA (ng/mL) & $12.8(2.7-59.7)$ & I.3 (0.9-2.0) & $<0.001$ \\
\hline CAI53 (U/mL) & $81.7(25.3-287.0)$ & $9.8(7.3-13.4)$ & $<0.001$ \\
\hline ER (Positive, \%) & $119(56.4)$ & $138(64.2)$ & 0.100 \\
\hline PR (Positive, \%) & $115(54.5)$ & $135(62.8)$ & 0.082 \\
\hline HER-2 status (Positive, \%) & $76(36.0)$ & $92(42.8)$ & 0.153 \\
\hline \multicolumn{4}{|l|}{$\begin{array}{l}\text { Tumor molecular } \\
\text { subtype }\end{array}$} \\
\hline Luminal-A & $|2|(57.3)$ & $107(49.8)$ & 0.117 \\
\hline Luminal-B & 49 (23.2) & $46(21.4)$ & 0.651 \\
\hline HER 2+ & $20(9.5)$ & $32(14.9)$ & 0.088 \\
\hline TNBC & $21(10.0)$ & $30(14.0)$ & 0.203 \\
\hline
\end{tabular}

Abbreviations: BMI, body mass index; FPG, fasting plasma glucose; WBC, white blood cell; MPV, mean platelet volume; PDW, platelet distribution width; ER, estrogen receptor; PR, progesterone receptor; HER2, human epidermal growth factor receptor 2; TNBC, triple-negative breast cancer. 
CEA, and CA153 levels. However, menopausal status, fasting plasma glucose, albumin, creatinine, platelet count, platelet distribution width, and tumor molecular subtype in two groups had no difference.

MPV levels were shown using menopausal status and triple-negative breast cancer (TNBC) molecular subtype to stratify the BC patients (Figure S1). There was a difference in MPV in premenopausal non-TNBC patients according to liver metastases status $(9.3 \pm 1.3 \mathrm{fL}$ vs $7.8 \pm 1.3 \mathrm{fL}, \mathrm{p}<0.001)$ (Figure S2). In postmenopausal non-TNBC patients, compared with the patients with liver metastases, higher MPV levels were observed in patients without liver metastases (9.1 $\pm 1.0 \mathrm{fL}$ vs $8.3 \pm 1.5 \mathrm{fL}, \mathrm{p}<0.001$ ) (Figure S3). In addition, there was a significant difference in MPV in postmenopausal TNBC patients according to liver metastases status $(9.3 \pm 1.6 \mathrm{fL}$ vs $7.8 \pm 1.0 \mathrm{fL}, \mathrm{p}=0.003$ ) (Figure S3).

MPV levels were presented using menopausal status and human epidermal growth factor receptor (HER2) positive molecular subtype to stratify the $\mathrm{BC}$ patients (Figure S4). Similar to the postmenopausal non-TNBC patterns, there was a difference in MPV in premenopausal
non-HER2+ BC patients according to liver metastases status $(9.0 \pm 1.3 \mathrm{fL}$ vs $8.1 \pm 1.3 \mathrm{fL}, \mathrm{p}<0.001)$ (Figure S5). In postmenopausal HER2+ BC patients, MPV levels were higher in patients without liver metastases compared with those in patients with liver metastases $(9.5 \pm 1.0 \mathrm{fL}$ vs 7.7 $\pm 0.5 \mathrm{fL}, \mathrm{p}=0.026$ ) (Figure S6). In addition, a notable difference in MPV was found in postmenopausal nonHER2+ BC patients according to liver metastases status $(9.1 \pm 1.1 \mathrm{fL}$ vs $8.2 \pm 1.4 \mathrm{fL}, \mathrm{p}<0.001)$ (Figure S6).

The platelet indices in $\mathrm{BC}$ patients are shown in Table 2. In the group with non-liver metastases, platelet distribution width was significantly associated with tumor $\mathrm{N}$ stage. In the group with liver metastases, there were no differences of platelet indices observed in liver tumor nodules, liver tumor size, and extrahepatic involvement.

The prevalence of liver metastases was calculated by the quartiles of MPV levels (Figure 1). The prevalence rate of liver metastases in Q1, Q2, Q3, and Q4 was 82.3\% (93/ 113), 50.5\% (52/103), 27.0\% (30/111), and 36.4\% (36/99), respectively. The prevalence rate of liver metastases in Q1 was significantly higher than that in Q2, Q3 and Q4. The

Table 2 Platelet Indices In BC Patients

\begin{tabular}{|c|c|c|c|c|c|c|}
\hline Variables & $\operatorname{PLT}\left(\times 10^{9} / \mathrm{L}\right)$ & $P$ value & MPV(fL) & $P$ value & PDW(\%) & $P$ value \\
\hline \multicolumn{7}{|c|}{ Without liver metastases } \\
\hline $\begin{array}{l}\text { Tumor T stage } \\
\qquad \begin{array}{l}\mathrm{TI}+\mathrm{T} 2 \\
\mathrm{~T} 3+\mathrm{T} 4\end{array}\end{array}$ & $\begin{array}{l}235.0(51.3) \\
245.2(64.4)\end{array}$ & 0.544 & $\begin{array}{l}9.1(1.2) \\
9.1(1.3)\end{array}$ & 0.985 & $\begin{array}{l}16.7(1.0) \\
17.2(0.7)\end{array}$ & 0.136 \\
\hline $\begin{array}{l}\text { Tumor N stage } \\
\text { No } \\
\text { NI-3 }\end{array}$ & $\begin{array}{l}234.3(50.8) \\
246.1(60.8)\end{array}$ & 0.321 & $\begin{array}{l}9.1(1.1) \\
8.7(1.5)\end{array}$ & 0.115 & $\begin{array}{l}16.7(1.0) \\
17.2(0.7)\end{array}$ & 0.046 \\
\hline $\begin{array}{l}\text { Tumor Size } \\
\qquad 2.5 \mathrm{~cm} \\
\geq 2.5 \mathrm{~cm}\end{array}$ & $\begin{array}{l}235.0(50.9) \\
237.1(55.9)\end{array}$ & $0.81 \mathrm{I}$ & $\begin{array}{l}9.1(1.1) \\
9.0(1.6)\end{array}$ & 0.781 & $\begin{array}{l}16.7(1.0) \\
16.9(1.1)\end{array}$ & 0.198 \\
\hline \multicolumn{7}{|l|}{ With liver metastases } \\
\hline $\begin{array}{l}\text { Liver Tumor Nodules } \\
\quad<2 \\
\geq 2\end{array}$ & $\begin{array}{l}239.8(85.5) \\
239.8(85.5)\end{array}$ & 0.975 & $\begin{array}{l}8.4(1.3) \\
8.2(1.4)\end{array}$ & 0.390 & $\begin{array}{l}16.9(1.6) \\
17.0(1.4)\end{array}$ & 0.700 \\
\hline $\begin{array}{l}\text { Liver Tumor Size } \\
\qquad \leq 50 \mathrm{~mm} \\
\quad>50 \mathrm{~mm}\end{array}$ & $\begin{array}{l}241.8(80.7) \\
228.6(84.0)\end{array}$ & 0.385 & $\begin{array}{l}8.1(1.3) \\
8.6(1.6)\end{array}$ & 0.052 & $\begin{array}{l}16.9(1.5) \\
17.4(1.2)\end{array}$ & 0.069 \\
\hline $\begin{array}{l}\text { Extrahepatic Involvement } \\
\text { Liver only involved } \\
\text { Liver + other sites }\end{array}$ & $\begin{array}{l}241.0(82.7) \\
231.3(70.8)\end{array}$ & 0.558 & $\begin{array}{l}8.2(1.4) \\
8.6(1.6)\end{array}$ & 0.168 & $\begin{array}{l}16.9(1.5) \\
17.0(1.3)\end{array}$ & 0.853 \\
\hline
\end{tabular}

Note: alung, bone, and brain.

Abbreviations: BMI, body mass index; PLT, platelet count; MPV, mean platelet volume; PDW, platelet distribution width. 


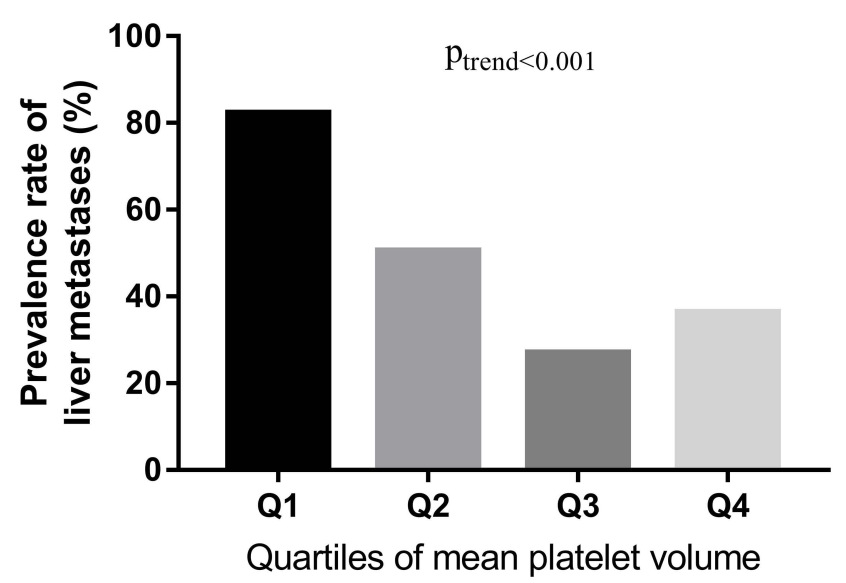

Figure I The prevalence rate of liver metastases (\%) in BC patients according to MPV quartiles.

Notes: Figure I shows the association between MPV levels and prevalence rate of liver metastases in BC patients (\%). Participants were stratified into quartiles according to their MPV levels. The prevalence of liver metastases is calculated by the quartiles of MPV levels.

results indicated that the prevalence of liver metastases reduced as MPV quartiles increased $(\mathrm{p}<0.001)$.

The risks of liver metastases according to MPV quartiles are shown in Table 3. After adjusting for age, body mass index, menopausal status, fasting plasma glucose, albumin, haemoglobin, creatinine, and white blood cell, the prevalence risk of liver metastases for the highest quartile of MPV was 1.757 (1.024-3.015).

\section{Discussion}

Our study demonstrated that BC patients with liver metastases had lower MPV levels compared to BC patients without metastases. Furthermore, MPV was independently associated with the presence of liver metastases.

Despite the best current medical and surgical treatment, the overall prognosis of $\mathrm{BC}$ patients with liver metastases remains poor. Therefore, it is of great importance to identify novel biomarkers for treatment. The interaction of cancer cells with platelets leads to platelet activation, and, on the other hand, platelet activation is strongly instrumental to the pro- carcinogenic and pro-metastatic activities of platelets. ${ }^{17}$ In breast cancer, platelet-derived growth factor (PDGF) expression is associated with biological aggressiveness via NFkappaB signaling pathway. ${ }^{18,19}$ Platelet-derived lysophosphatidic acid accelerates osteolytic bone metastases. ${ }^{20}$ In addition, platelet releasate increases $\mathrm{BC}$ cell proliferation through VEGF-integrin cooperative signaling. ${ }^{21}$ A recent study found that ticagrelor, a P2Y12 inhibitor, could reduce tumor growth and metastasis in human and murine breast cancer cells. $^{22}$

In agreement with the studies above, our study confirmed the important role of activated platelets in BC. Moreover, our study can form the basis for further mechanistic studies and ultimately aid in patient-tailored selection of therapeutic strategies. Monitoring the changes of MPV maybe contribute to early detection of liver metastases in $\mathrm{BC}$ patients. In addition, patient stratification approach utilising menopausal status, MPV levels, and molecular subtype may be helpful for metastatic evaluation. In addition, the results underlined the importance of activated platelets involved in liver metastases and pointed out the need for further mechanistic research.

The mechanisms underlying the association between MPV and survival in BC patients with liver metastases remain unclear. Cancer changes platelet behavior by directly inducing tumor-platelet aggregates, triggering platelet granule and extracellular vesicle release, altering platelet phenotype and platelet RNA profiles, and enhancing thrombopoiesis. ${ }^{23} \mathrm{MPV}$ is an early indicator of activated platelets. Strong evidence revealed that larger platelets are more metabolically and enzymatically active than smaller platelets. Direct or indirect interaction of platelets induces cancer cell plasticity and enhances survival and extravasation of circulating cancer cells during dissemination. $^{24}$ Platelets physically and functionally interact with tumor cells through surface receptors including integrins. The main role of two platelet integrins, $\alpha 6 \beta 1$ and $\alpha \mathrm{IIb} \beta 3$, was proposed to participate in tumor metastasis via platelet adhesion and aggregation at sites of

Table 3 The Risks Of Liver Metastases In BC Patients According To MPV Quartiles

\begin{tabular}{|l|l|l|l|l|}
\hline & Cases & Controls & OR (95\% Cl) & p-value \\
\hline QI $(\leq 7.8 \mathrm{fL})$ & 93 & 20 & I (reference) & \\
Q2 $(7.9-8.5 \mathrm{fL})$ & 52 & $5 \mathrm{I}$ & $0.267(0.134-0.530)$ & $<0.00 \mathrm{I}$ \\
Q3 (8.6-9.4 fL) & 30 & $8 \mathrm{I}$ & $0.072(0.034-0.152)$ & $<0.00 \mathrm{I}$ \\
Q4 ( $\geq 9.5 \mathrm{fL})$ & 36 & 63 & $0.137(0.066-0.28 \mathrm{I})$ & $<0.00 \mathrm{I}$ \\
\hline
\end{tabular}

Note: Logistic regression analysis adjusted for age.

Abbreviations: BMI, menopausal status; FPG, albumin, haemoglobin, creatinine, and WBC; $\mathrm{Cl}$, confidence interval. 
vascular injury. ${ }^{25}$ The secretory factors released by activated platelets promote chemokines, proteolytic enzymes and microparticles within the microenvironment and accelerate tumor cell invasion. ${ }^{26}$ In addition, aspirin and clopidogrel inhibit the expression of $\alpha$-granule-stored proteins that are involved in heterotypic interactions between platelets/leukocytes and the endothelium. ${ }^{27}$

In accord with our results, Tuncel et al reported that increased MPV was a prognostic factor for metastatic colorectal cancer patients treated with bevacizumab-combined chemotherapy. ${ }^{28} \mathrm{Gu}$ et al found that high pre-treatment MPV levels in invasive breast cancer patients were associated with worse clinicopathologic features. ${ }^{29}$ Lian et al observed that high baseline MPV levels were associated with increased metastases. ${ }^{30}$ These findings are also consistent with the current knowledge that anti-platelet is considered to be a part of cancer adjuvant therapy. ${ }^{31}$

There are several limitations of this study. First, the current study was a retrospective analysis with a limited number of patients. Thus, a more thorough investigation in a larger series of patients is necessary to confirm the results. Second, the mechanisms underlying the involvement of MPV in BC patients with liver metastases remain unclear. Further experiments which are designed to identify the precise mechanism are warranted. Third, the patients were composed of only Chinese. External validation is still needed to confirm whether our results can be generalized to a new patient population.

\section{Outlook}

Breast cancer is a heterogeneous disease. Different molecular subtypes of breast cancer can change longitudinally during treatment resulting in treatment failures and requiring different therapeutic approaches. ${ }^{32}$ The subclassification of breast cancers will allow physicians to tailor effective treatments to target this heterogeneity. DNA sequencing, mRNA micro-arrays, next-generation sequencing, and an array of proteomics assays have allowed profiling of large numbers of tumors based on mutational profiles and aberrant gene and protein expression. ${ }^{33}$ Multiomic approach may discover a unique molecular signature of the TNBC subtype and could be of great clinical utility for development of predictive diagnosis and targeted treatments. $^{34,35}$

In summary, MPV is reduced in $\mathrm{BC}$ patients with liver metastases compared with $\mathrm{BC}$ patients without metastases. Moreover, MPV is independently associated with the presence of liver metastases. Further studies are needed.

\section{Funding}

This work was supported by grants from the Harbin Medical University Cancer Hospital (JJZD2017-05) and from Nn10 (003) program of Harbin Medical University Cancer Hospital.

\section{Disclosure}

The authors report no conflicts of interest in this work.

\section{References}

1. DeSantis CE, Ma J, Goding SA, Newman LA, Jemal A. Breast cancer statistics, 2017, racial disparity in mortality by state. $C A$ Cancer J Clin. 2017;67:439-448. doi:10.3322/caac.21412

2. Bale R, Putzer D, Schullian P. Local treatment of breast cancer liver metastasis. Cancers (Basel). 2019;11:1341.

3. Polivka J, Kralickova M, Polivka J, Kaiser C, Kuhn W, Golubnitschaja O. Mystery of the brain metastatic disease in breast cancer patients: improved patient stratification, disease prediction and targeted prevention on the horizon. EPMA J. 2017;8:119-127. doi:10.1007/s13167-017-0087-5

4. Smokovski I, Risteski M, Polivka J, et al. Postmenopausal breast cancer: European challenge and innovative concepts. EPMA J. 2017;8:159-169. doi:10.1007/s13167-017-0094-6

5. Fröhlich H, Patjoshi S, Yeghiazaryan K, Kehrer C, Kuhn W, Golubnitschaja O. Premenopausal breast cancer: potential clinical utility of a multi-omics based machine learning approach for patient stratification. EPMA J. 2018;9:175-186. doi:10.1007/s13167-018-0131-0

6. Zubor P, Kubatka P, Kajo K, et al. Why the gold standard approach by mammography demands extension by multiomics? Application of liquid biopsy miRNA profiles to breast cancer disease management. Int J Mol Sci. 2019;20:2878.

7. Suzuki K, Aiura K, Kitagou M, et al. Platelets counts closely correlate with the disease-free survival interval of pancreatic cancer patients. Hepatogastroenterology. 2004;51(57):847-853.

8. Qiu J, Yu Y, Fu Y, Ye F, Xie X, Lu W. Preoperative plasma fibrinogen, platelet count and prognosis in epithelial ovarian cancer. $J$ Obstet Gynaecol Res. 2012;38(4):651-657. doi:10.1111/j.14470756.2011.01780.x

9. Ekici H, Malatyalioglu E, Kokcu A, Kurtoglu E, Tosun M, Celik H. Do leukocyte and platelet counts have benefit forlpreoperative evaluation of endometrial cancer. Asian Pac J Cancer Prev. 2015;16 (13):5305-5310. doi:10.7314/apjcp.2015.16.13.5305

10. Long Y, Wang T, Gao Q, Zhou C. Prognostic significance of pretreatment elevated platelet count in patients with colorectal cancer: a meta-analysis. Oncotarget. 2016;7. doi:10.18632/oncotarget. v7i49

11. Pietrzyk L, Plewa Z, Denisow-Pietrzyk M, Zebrowski R, Torres K. Diagnostic power of blood parameters as screening markers in gastric cancer patients. Asian Pac J Cancer Prev. 2016;17(9):4433-4437.

12. Korniluk A, Koper-Lenkiewicz OM, Kamińska J, Kemona H, Dymicka-Piekarska V. Mean platelet volume (MPV): new perspectives for an old marker in the course and prognosis of inflammatory conditions. Mediators Inflamm. 2019;2019:9213074. doi:10.1155/2019/9213074

13. Kemal Y, Demirağ G, Ekiz K, Yücel I. Mean platelet volume could be a useful biomarker for monitoring epithelial ovarian cancer. J Obstet Gynaecol. 2014;34:515-518. doi:10.3109/ 01443615.2014 .912620

14. Kumagai S, Tokuno J, Ueda Y, et al. Prognostic significance of preoperative mean platelet volume in resected non-small-cell lung cancer. Mol Clin Oncol. 2015;3:197-201. doi:10.3892/mco.2014.436 
15. Shen XM, Xia YY, Lian L, et al. Mean platelet volume provides beneficial diagnostic and prognostic information for patients with resectable gastric cancer. Oncol Lett. 2016;12:2501-2506. doi: $10.3892 /$ ol.2016.4913

16. Tanriverdi O, Menekse S, Teker F, et al. The mean platelet volume may predict the development of isolated bone metastases in patients with breast cancer: a retrospective study of the Young Researchers Committee of the Turkish Oncology Group (TOG). J Buon. 2016;21:840-850.

17. Gresele P, Momi S, Malvestiti M, Sebastiano M. Platelet-targeted pharmacologic treatments as anti-cancer therapy. Cancer Metastasis Rev. 2017;36:331-355. doi:10.1007/s10555-017-9679-8

18. Carvalho I, Milanezi F, Martins A, Reis RM, Schmitt F. Overexpression of platelet-derived growth factor receptor alpha in breast cancer is associated with tumour progression. Breast Cancer Res. 2005;7(5):R78895. doi:10.1186/bcr949

19. Kang DW, Min D. Platelet derived growth factor increases phospholipase D1 but not phospholipase D2 expression via NFkappaB signaling pathway and enhances invasion of breast cancer cells. Cancer Lett. 2010;294(1):125-133. doi:10.1016/j.canlet.2010.01.031

20. Boucharaba A, Serre CM, Grès S, et al. Platelet-derived lysophosphatidic acid supports the progression of osteolytic bone metastases in breast cancer. $J$ Clin Invest. 2004;114(12):1714-1725. doi:10.1172/JCI22123

21. Jiang L, Luan Y, Miao X, et al. Platelet releasate promotes breast cancer growth and angiogenesis via VEGF-integrin cooperative signalling. Br J Cancer. 2017;117:695-703. doi:10.1038/bjc.2017.214

22. Gareau AJ, Brien C, Gebremeskel S, Liwski RS, Johnston B, Bezuhly M. Ticagrelor inhibits platelet-tumor cell interactions and metastasis in human and murine breast cancer. Clin Exp Metastasis. 2018;35:25-35. doi:10.1007/s10585-018-9874-1

23. Xu XR, Yousef GM, Ni H. Cancer and platelet crosstalk: opportunities and challenges for aspirin and other antiplatelet agents. Blood. 2018;131:1777-1789. doi:10.1182/blood-2017-05-743187

24. Wang $\mathrm{S}, \mathrm{Li} \mathrm{Z}, \mathrm{Xu} \mathrm{R}$. Human cancer and platelet interaction, a potential therapeutic target. Int J Mol Sci. 2018;19:1246.

25. Lavergne M, Janus-Bell E, Schaff M, Gachet C, Mangin PH. Platelet integrins in tumor metastasis: do they represent a therapeutic target? Cancers (Basel). 2017;9:133. doi:10.3390/cancers9100133

26. Schlesinger M. Role of platelets and platelet receptors in cancer metastasis. J Hematol Oncol. 2018;11:125. doi:10.1186/s13045-0180669-2
27. Huong PT, Nguyen LT, Nguyen X-B, Lee SK, Bach D-H. The role of platelets in the tumor-microenvironment and the drug resistance of cancer cells. Cancers (Basel). 2019;11:240. doi:10.3390/cancers 11020240

28. Tuncel T, Ozgun A, Emirzeoglu L, Celik S, Bilgi O, Karagoz B. Mean platelet volume as a prognostic marker in metastatic colorectal cancer patients treated with bevacizumab-combined chemotherapy. Asian Pac J Cancer Prev. 2014;15:6421-6423. doi:10.7314/ apjcp.2014.15.15.6421

29. Gu M, Zhai Z, Huang L, et al. Pre-treatment mean platelet volume associates with worse clinicopathologic features and prognosis of patients with invasive breast cancer. Breast Cancer. 2016;23:752760. doi:10.1007/s12282-015-0635-6

30. Lian L, Xia YY, Zhou C, et al. Mean platelet volume predicts chemotherapy response and prognosis in patients with unresectable gastric cancer. Oncol Lett. 2015;10:3419-3424. doi:10.3892/ ol.2015.3784

31. Palacios-Acedo AL, Mège D, Crescence L, Dignat-George F, Dubois C, Panicot-Dubois L. Platelets, thrombo-inflammation, and cancer: collaborating with the enemy. Front Immunol. 2019;10:1805. doi:10.3389/fimmu.2019.01805

32. Golubnitschaja O, Yeghiazaryan K, Stricker H, Trog D, Schild HH, Berliner L. Patients with hepatic breast cancer metastases demonstrate highly specific profiles of matrix metalloproteinases MMP-2 and MMP-9 after SIRT treatment as compared to other primary and secondary liver tumours. BMC Cancer. 2016;16:357. doi:10.1186/ s12885-016-2382-2

33. Golubnitschaja O, Polivka J, Yeghiazaryan K, Berliner L. Liquid biopsy and multiparametric analysis in management of liver malignancies: new concepts of the patient stratification and prognostic approach. EPMA J. 2018;9:271-285. doi:10.1007/s13167-018-01466

34. Zubor P, Kubatka P, Dankova Z, et al. miRNA in a multiomic context for diagnosis, treatment monitoring and personalized management of metastatic breast cancer. Future Oncol. 2018;14:1847-1867. doi:10.2217/fon-2018-0061

35. Golubnitschaja O, Filep N, Yeghiazaryan K, Blom HJ, HofmannApitius M, Kuhn W. Multi-omic approach decodes paradoxes of the triple-negative breast cancer: lessons for predictive, preventive and personalised medicine. Amino Acids. 2018;50:383-395. doi:10.1007/ s00726-017-2524-0

\section{Publish your work in this journal}

Cancer Management and Research is an international, peer-reviewed open access journal focusing on cancer research and the optimal use of preventative and integrated treatment interventions to achieve improved outcomes, enhanced survival and quality of life for the cancer patient.
The manuscript management system is completely online and includes a very quick and fair peer-review system, which is all easy to use. Visit http://www.dovepress.com/testimonials.php to read real quotes from published authors. 